\title{
The Future of Gaming Disorder Research and Player Protection: What Role Should the Video Gaming Industry and Researchers Play?
}

\author{
Mark D. Griffiths ${ }^{1}$ (D) Halley M. Pontes ${ }^{2}$
}

Published online: 18 July 2019

(C) The Author(s) 2019

\begin{abstract}
In May 2019, the World Health Organization (WHO) officially included gaming disorder (GD) in the eleventh revised edition of the International Classification of Diseases. Although the video game industry does not accept the WHO's decision to class GD as a genuine mental disorder, there is now arguably an onus on the video game industry to develop and undertake responsible gaming initiatives aimed at player protection and harm minimization. The present paper argues that the gaming industry does not have to "reinvent the wheel" as there are many responsible gaming tools and initiatives used by the gambling industry that they could implement (e.g., limit-setting, self-exclusions, personalized messaging, pop-up reminders). The paper also argues that like the gambling industry, the video game industry has an abundance of high-quality data in the form of player account data (i.e., behavioral tracking data) and that researchers should work collaboratively with the gaming industry to use such data to learn more about the acquisition, development, and maintenance of gaming and GD among its clientele. It is also noted that while there is the need for such cooperation, the integrity of independent research should not be jeopardized nor undermined in this process. In addition to the clear need of establishing a scientific partnership between gaming operators and researchers, the paper also outlines several steps and recommendations to improve the overall quality of research in GD.
\end{abstract}

Keywords Gaming disorder · Gaming addiction · Gaming industry · Social responsibility · Harm minimization · Big data

Mark D. Griffiths

mark.griffiths@ntu.ac.uk

1 Psychology Department, Nottingham Trent University, 50 Shakespeare Street, Nottingham NG1 4FQ, UK

2 Division of Psychology, School of Medicine, University of Tasmania, Launceston, Australia 
On May 25, 2019, the World Health Organization (WHO) officially included gaming disorder (GD) in the latest (eleventh) revision of the International Classification of Diseases (ICD-11; WHO 2019). High-profile debates in both the mass media and learned journals about whether GD should be classed as an official mental disorder have raged ever since the American Psychiatric Association (2013) included Internet Gaming Disorder (IGD) as a tentative disorder in the latest (fifth) edition of the Diagnostic and Statistical Manual of Mental Disorders (e.g., Aarseth et al. 2017; Billieux et al. 2017; European Games Developer Foundation 2018; Griffiths et al. 2016, 2017; King and Delfabbro 2013; King and Gaming Industry Response Consortium 2018; Kuss et al. 2017; Petry et al. 2014; Rumpf et al. 2018; Saunders et al. 2017).

Although (predictably) the video game industry does not accept the WHO's decision to class GD as a genuine mental disorder (European Games Developer Foundation 2018), there is now arguably an onus on the video game industry to develop and undertake responsible gaming initiatives aimed at player protection and harm minimization. In the same way that the gambling industry has had to embrace social responsibility and a duty of care towards their clientele in efforts to prevent problematic gambling, the video game industry should now do the same to prevent GD, as has been proposed before by various scholars (e.g., van Rooij et al. 2010; Yousafzai et al. 2014).

This is an area that the video game industry does not have to "reinvent the wheel" as there are many responsible gaming tools and initiatives they could utilize by "borrowing" from the gambling industry (i.e., sharing best practice). Over the past 15 years, there has been a large increase in both online and land-based gambling operators introducing a wide range of responsible gambling tools including (but not limited to) pre-commitment limitsetting tools (i.e., tools allowing gamblers to set the amount of time and money they are prepared to spend gambling), self-exclusion tools (e.g., tools allowing gamblers to temporarily or permanently exclude themselves from gambling at specific online gambling websites for particular periods of time), "cool-off" periods (e.g., short mandatory breaks from gambling that provide players with an opportunity for a "reflective" time-out), personalized messaging (e.g., providing information to gamblers via text-messaging and/ or email about aspects of their gambling such as how much money they have lost in a specified time period), pop-up messaging (e.g., messages appearing on slot machines or on electronic devices while gambling to inform players about the amount of time they have been playing and/or the number of consecutive games they have played without a break), and behavioral tracking tools (e.g., tools like PlayScan which analyze gambling behavior in real time and provides feedback to players about whether their gambling is risky or not) (Harris and Griffiths 2017).

All of these tools could be adapted and utilized by the video game industry to help protect their clientele and minimize potential harms stemming from excessive gaming. In the past year, and as part of their commitment to protecting social network users from excessive use, social media operators such as Facebook and Instagram and smartphone operators such as Apple have introduced a portfolio of responsible social media use tools closely modeled on those used by the gambling industry (Booth 2018; Field et al. 2018). This came about (at least in part) because of the many academic studies on problematic social media use and "social media addiction" (for an overview of such research, see Kuss and Griffiths 2017). Given that gambling operators and the social media operators have both introduced tools to help promote responsible gambling/social media use and prevent 
excessive use of gambling/social media, there is no good reason for video game operators not to do the same. If they do not do it voluntarily, media regulators should be given legal powers to force video game operators to introduce responsible gaming tools as part of their commitment to social responsibility and duty of care of their clientele. This is particularly important and timely given that GD is now an officially recognized mental health disorder and therefore may pose a potential public health issue.

Prevention of problematic video gaming and GD cannot be overcome without all major stakeholders playing their part - and that includes the video gaming industry. In the gambling studies field, it is now becoming commonplace (although admittedly not without controversy) for academic researchers to collaborate with gambling operators by conducting independent research. While anyone who is anti-gambling will probably view such collaborations as morally reprehensible, we would argue that such collaborations have brought about methodological innovation and access to high-quality data that were simply unobtainable previously by traditional methods (e.g., survey-based research). The most obvious innovation has been in the area of sharing and data mining player account data derived from loyalty cards, player cards, and/or online gambling websites (i.e., "behavioral tracking" data) (Griffiths 2014; Griffiths and Whitty 2010).

Online tracking data are commonly used in numerous contexts by many companies to better understand human behavior. The use of such data by the gambling operators, gaming operators, and social media operators is no different. Most people probably view the internet as a highly anonymous medium but rest assured, someone, somewhere, is monitoring everything an individual does online - and that includes the video game operators. Working in collaboration with video game operators is arguably (at present) the only way to get access to such high-quality data that will assist researchers in better understanding risk factors associated with problematic gaming and GD.

Data from online environments provide potential advantages to many sectors (particularly those in the fields of marketing and advertising). This is because every click and transaction of every customer is automatically stored in a database and provides high-quality data for those who know what to do with it. This is very much in contrast to surveys, experiments, and participant and nonparticipant observation, where such data have to be gathered at high costs, with significant amounts of manual work involved, and may be prone well-known errors and biases.

Within the gambling studies field, a number of different research teams across the world (including that of the first author) have now been given access to behavioral tracking data of gamblers. Such data include account data (date of birth, gender, geographic location, etc.), game data (game type, time spent on games, money spent on games, amount of losses/winnings, amount of money spent, number of bets/spins, session time), financial data (such as number and amount of money deposits, number of money withdrawals, number of accounts, etc.), responsible gaming limit data (e.g., time and money spending limits, changes of limits, and the number of times that limits are reached), and miscellaneous data (number of times that customer services have been contacted, number of active days gambled, number of "cool-off periods," etc.).

Many of these types of data are also held by those who operate online video game sites and servers and could potentially be used for research purposes. Online gaming sites and servers typically collect three types of information. These are (i) personal details provided by a user (e.g., name, email address, telephone number, address, gender, etc.), (ii) usage data collected automatically as the user clicks from one webpage to another (e.g., how users access the site, type of web browser used, time spent logged onto the site, etc.), and (iii) in-game behaviors (e.g., types of activities engaged in the game, preferred content, etc.). Almost any variable (beyond the usual demographic ones such as age, gender, education, relationship status, etc.) 
could be examined as a risk and/or protective factor in the context of video gaming. Access to such data sets may provide insights into a number of important areas such as transitions from gaming to social gambling and how gaming might be integrated with other online behaviors (such as gambling and the buying of loot boxes) (Brooks and Clark 2019; Griffiths 2018; King and Delfabbro 2018; Zendle and Cairns 2018).

The types of studies that are now being published in the gambling studies field using behavioral tracking data are difficult to be conducted without stakeholder involvement from the gambling industry. The types of innovative research that have been published have included the (i) identification of problem gambling markers in online gambling (Braverman and Shaffer 2012; Dragičević et al. 2011; LaBrie and Shaffer 2011; Xuan and Shaffer 2009), (ii) developing measures of "gambling intensity" (Auer and Griffiths 2014), (iii) usage and evaluation of responsible gambling tools such as limit-setting (Auer and Griffiths 2013; Broda et al. 2008; Nelson et al. 2008), pop-up messaging (Auer and Griffiths 2015a; Auer et al. 2014), loss-limit reminders (Auer et al. 2018), personalized messaging (Auer and Griffiths 2015b, 2016), (iv) relationship between gambling behavior and alcohol use (Leino et al. 2017), (v) relationship between gambling behavior and structural characteristics (Leino et al. 2015), (vi) relationship between gambling behavior and the environments in which individuals gamble (Sagoe et al. 2018), (vii) effects of limit-setting on gambling loyalty (Auer et al. 2019), and the relationship between what gamblers think they did and what they actually did (Auer and Griffiths 2017, 2018; Braverman et al. 2014).

Many of these emerging innovative gambling studies could be replicated and/or adapted to video gaming environments if researchers collaborate with video game operators and/or have access to their tracking data. Although a few video gaming studies have been previously published using ingame behavioral data provided by gaming operators (e.g., Sony Online Entertainment), these are very scarce and essentially aimed to examine non-health-related aspects of the gaming experience associated to gender-based differences among players (Williams et al. 2009) and social/interactive, motivation factors within gaming environments (Williams et al. 2008). To the best of the authors' knowledge, no previous similar study using unobtrusively collected game-based behavioral data focusing on problematic gaming and GD has been conducted to date.

In addition to the clear need of establishing a scientific partnership between gaming operators and researchers, several steps and recommendations can be equally considered to be implemented in future research to improve the overall quality of research in GD. Thus, we propose the following five recommendations for future areas of focus in GD research:

1. Focus on open science: Researchers should be encouraged to implement data-sharing procedures and transparency of research procedures by pre-registering their upcoming studies on established platforms such as the Open Science Framework (https://osf.io). Although this may not be entirely sufficient to tackle potential replicability issues, it will likely increase the robustness and transparency of future research.

2. Focus on establishing a robust assessment: Like any other clinical psychological phenomena, researchers should aim to establish a robust clinical assessment framework for GD based on the latest framework developed by the WHO. This will facilitate comparisons between international studies conducted on GD and at the same time reduce the residual conceptual heterogeneity that still exists in the field. Similar to what happened when the DSM-5 was released, it is expected that the adoption of a robust and consistent assessment framework for GD will likely increase the quantity and quality of cross-cultural research. 
3. Focus on clinical research: Due to the relatively low prevalence rates of behavioral addictions, it is unlikely that GD may become endemic and highly prevalent worldwide. However, this should not hinder future efforts by researchers to conduct clinical research as this type of research is essential for refining existing psychometric assessment tools and helping researchers derive reliable clinical "gold standards" that can be used in the assessment of GD in order to enhance diagnostic accuracy in clinical milieus. Furthermore, clinical research aimed at providing reliable information on the etiology and clinical course of GD is needed as a spontaneous remission in behavioral addictions is relatively common and poorly understood.

4. Focus on prevention and treatment research: Given that very few studies on problematic gaming and GD have aimed at exploring preventive and treatment avenues for GD, future research is needed to develop preventive measures and efficacious treatment approaches for GD. Such new measures should be systematically and empirically tested and shared among practitioners to help clinicians improve the overall quality of life and wellbeing of disordered gamers. The responsibility of helping disordered gamers is not entirely on the video game industry's side as researchers and clinicians should also help the development in refinement of preventive and treatment approaches.

5. Focus on psychological motivations: Although a relatively large number of studies have examined the interplay between psychological motivations and broad game play behaviors, further research investigating the specific intricacies between psychological motivations and GD should be carried out as opposed to only examining broad motivations underpinning gaming. Such studies will help informing the role of psychological motivations in the development of GD.

In conclusion, it is argued that establishing a good level of cooperation between video game operators and researchers is timely given that GD has been recognized as a mental health disorder by the WHO. It is also worth mentioning that while there is the need for such cooperation, the integrity of independent research should not be jeopardized nor undermined in this process. Thus, achieving this cooperation step is paramount if the video gaming industry is to take social responsibility practices seriously and embed them in their mission and commitment to player protection and harm minimization.

\section{Compliance with Ethical Standards}

Conflict of Interest The first author's university is currently receiving funding from Norsk Tipping (the gambling operator owned by the Norwegian Government). The first author has also received funding for a number of research projects in the area of gambling education for young people, social responsibility in gambling, and gambling treatment from Gamble Aware (formerly the Responsibility in Gambling Trust), a charitable body which funds its research program based on donations from the gambling industry. The first author undertakes consultancy for various gaming companies in the area of social responsibility in gambling.

Ethical Approval Not applicable.

Informed Consent Not applicable.

Open Access This article is distributed under the terms of the Creative Commons Attribution 4.0 International License (http://creativecommons.org/licenses/by/4.0/), which permits unrestricted use, distribution, and reproduction in any medium, provided you give appropriate credit to the original author(s) and the source, provide a link to the Creative Commons license, and indicate if changes were made. 


\section{References}

Aarseth, E., Bean, A. M., Boonen, H., Colder Carras, M., Coulson, M., Das, D., et al. (2017). Scholars' open debate paper on the World Health Organization ICD-11 Gaming Disorder proposal. Journal of Behavioral Addictions, 6, 267-270.

American Psychiatric Association. (2013). Diagnostic and statistical manual of mental disorders - text revision (Fifth ed.). Arlington, VA: American Psychiatric Publishing.

Auer, M., \& Griffiths, M. D. (2013). Voluntary limit setting and player choice in most intense online gamblers: An empirical study of gambling behaviour. Journal of Gambling Studies, 29, 647-660.

Auer, M., \& Griffiths, M. D. (2014). An empirical investigation of theoretical loss and gambling intensity. Journal of Gambling Studies, 30, 879-887.

Auer, M., \& Griffiths, M. D. (2015a). Testing normative and self-appraisal feedback in an online slot-machine pop-up message in a real-world setting. Frontiers in Psychology, 6, 339.

Auer, M., \& Griffiths, M. D. (2015b). The use of personalized behavioral feedback for problematic online gamblers: An empirical study. Frontiers in Psychology, 6, 1406.

Auer, M., \& Griffiths, M. D. (2016). Personalized behavioral feedback for online gamblers: A real world empirical study. Frontiers in Psychology, 7, 1875.

Auer, M., \& Griffiths, M. D. (2017). Self-reported losses versus actual losses in online gambling: An empirical study. Journal of Gambling Studies, 33, 795-806.

Auer, M., \& Griffiths, M. D. (2018). Cognitive dissonance, personalized feedback, and online gambling behavior: An exploratory study using objective tracking data and subjective self-report. International Journal of Mental Health and Addiction, 16, 631-641.

Auer, M., Malischnig, D., \& Griffiths, M. D. (2014). Is 'pop-up' messaging in online slot machine gambling effective? An empirical research note. Journal of Gambling Issues, 29, 1-10.

Auer, M., Hopfgartner, N., \& Griffiths, M. D. (2018). The effect of loss-limit reminders on gambling behavior: A real world study of Norwegian gamblers. Journal of Behavioral Addictions, 7, 1056-1067.

Auer, M., Hopfgartner, N., \& Griffiths, M. D. (2019). An empirical study of the effect of voluntary limit setting on gamblers' loyalty using behavioral tracking data. International Journal of Mental Health and Addiction. Epub ahead of print. https://doi.org/10.1007/s11469-019-00084-3

Billieux, J., King, D. L., Higuchi, S., Achab, S., Bowden-Jones, H., Hao, W., et al. (2017). Functional impairment matters in the screening and diagnosis of gaming disorder: Commentary on: Scholars' open debate paper on the World Health Organization ICD-11 Gaming Disorder proposal (Aarseth et al.). Journal of Behavioral Addictions, 6(3), 285-289.

Booth, C. (2018). Facebook and Instagram officially announce new tools to fight social media addiction. The Next Web, August 1. Retrieved July10, 2019, from: https://thenextweb.com/facebook/2018/08/01/socialmedia-addiction-facebook-instagram/

Braverman, J., \& Shaffer, H. (2012). How do gamblers start gambling: Identifying behavioural markers for highrisk internet gambling. European Journal of Public Health, 22(2), 273-278.

Braverman, J., Tom, M. A., \& Shaffer, H. J. (2014). Accuracy of self-reported versus actual online-gambling wins and losses. Psychological Assessment, 26, 865-877.

Broda, A., LaPlante, D. A., Nelson, S. E., LaBrie, R. A., Bosworth, L. B., \& Shaffer, H. J. (2008). Virtual harm reduction efforts for Internet gambling: Effects of deposit limits on actual Internet sports gambling behaviour. Harm Reduction Journal, 5, 27.

Brooks, G. A., \& Clark, L. (2019). Associations between loot box use, problematic gaming and gambling, and gambling-related cognitions. Addictive Behaviors, 96, 26-34.

Dragičević, S., Tsogas, G., \& Kudic, A. (2011). Analysis of casino online gambling data in relation to behavioural risk markers for high-risk gambling and player protection. International Gambling Studies, 11(3), 377-391.

European Games Developer Foundation (2018). Statement on WHO ICD-11 list and the inclusion of gaming. Retrieved July 10, 2019: http://www.egdf.eu/wp-content/uploads/2018/06/Industry-Statement-on-18-JuneWHO-ICD-11.pdf

Field, M., Archer, J., \& Mehta, A. (2018). 'Apple is Big Brother here': experts respond to the iPhone's antiaddiction features. Daily Telegraph, July 10. Retrieved May 31, 2019, from: https:/www.telegraph.co. uk/technology/2018/06/05/apple-big-brother-experts-respond-iphones-anti-addiction-features/

Griffiths, M.D. (2014). The use of behavioural tracking methodologies in the study of online gambling. SAGE Research Methods Cases. Retrieved July 10, 2019, from: https://doi.org/10.4135/978144627305013517480

Griffiths, M. D. (2018). Is the buying of loot boxes in videogames a form of gambling or gaming? Gaming Law Review, 22(1), 52-54.

Griffiths, M. D., \& Whitty, M. W. (2010). Online behavioural tracking in Internet gambling research: Ethical and methodological issues. International Journal of Internet Research Ethics, 3, 104-117. 
Griffiths, M. D., Van Rooij, A., Kardefelt-Winther, D., Starcevic, V., Király, O., ... Demetrovics, Z. (2016). Working towards an international consensus on criteria for assessing Internet Gaming Disorder: A critical commentary on Petry et al (2014). Addiction, 111, 167-175.

Griffiths, M. D., Kuss, D. J., Lopez-Fernandez, O., \& Pontes, H. M. (2017). Problematic gaming exists and is an example of disordered gaming. Journal of Behavioral Addictions, 6, 296-301.

Harris, A., \& Griffiths, M. D. (2017). A critical review of the harm-minimisation tools available for electronic gambling. Journal of Gambling Studies, 33, 187-221.

King, D. L., \& Delfabbro, P. H. (2013). Issues for DSM-5: video-gaming disorder? The Australian and New Zealand Journal of Psychiatry, 47(1), 20-22.

King, D. L., \& Delfabbro, P. H. (2018). Predatory monetization schemes in video games (e.g. 'loot boxes') and internet gaming disorder. Addiction, 113(11), 1967-1969.

King, D., \& Gaming Industry Response Consortium. (2018). Comment on the global gaming industry's statement on ICD-11 gaming disorder: A corporate strategy to disregard harm and deflect social responsibility? Addiction, 113, 2145-2146.

Kuss, D. J., \& Griffiths, M. D. (2017). Social networking sites and addiction: ten lessons learned. International Journal of Environmental Research and Public Health, 14, 311.

Kuss, D. J., Griffiths, M. D., \& Pontes, H. M. (2017). Chaos and confusion in DSM-5 diagnosis of Internet Gaming Disorder: Issues, concerns, and recommendations for clarity in the field. Journal of Behavioral Addictions, 6, 103-109.

LaBrie, R., \& Shaffer, H. (2011). Identifying behavioral markers of disordered internet sports gambling. Addiction Research and Theory, 19(1), 56-65.

Leino, T., Torsheim, T., Blaszczynski, A., Griffiths, M. D., Mentzoni, R., Pallesen, S., \& Molde, H. (2015). The relationship between structural characteristics and gambling behavior: A population based study. Journal of Gambling Studies, 31, 1297-1315.

Leino, T., Sagoe, D., Griffiths, M. D., Mentzoni, R. A., Pallesen, S., \& Molde, H. (2017). Gambling behavior in alcohol-serving and non-alcohol-serving venues: A study of electronic gaming machine players using account records. Addiction Research and Theory, 25, 201-207.

Nelson, S. E., LaPlante, D. A., Peller, A. J., Schumann, A., LaBrie, R. A., \& Shaffer, H. J. (2008). Real limits in the virtual world: Self-limiting behavior of Internet gamblers. Journal of Gambling Studies, 24(4), 463-477.

Petry, N. M., Rehbein, F., Gentile, D. A., Lemmens, J. S., Rumpf, H. J., Mößle, T., ...O'Brien, C. P. (2014). An international consensus for assessing internet gaming disorder using the new DSM-5 approach. Addiction, 109(9), 1399-1406.

Rumpf, H.-J., Achab, S., Billieux, J., Carragher, N., Demetrovics, Z., ... Poznyak, V. (2018). Including Gaming Disorder in the ICD-11: the need to do so from a clinical and public health perspective. Journal of Behavioral Addictions, 7, 556-561.

Sagoe, D., Pallesen, S., Griffiths, M. D., Mentzoni, R. A., \& Leino, T. (2018). Does the number of gambling terminals in a venue influence an individual's gambling behaviour? An empirical real world study. Frontiers in Psychology, 9, 158.

Saunders, J. B., Hao, W., Long, J., King, D. L., Mann, K., et al. (2017). Gaming disorder: Its delineation as an important condition for diagnosis, management and prevention. Journal of Behavioral Addictions, 6, 271279.

van Rooij, A. J., Meerkerk, G., Schoenmakers, T. M., Griffiths, M. D., \& van de Mheen, D. (2010). Video game addiction and social responsibility. Addiction Research and Theory, 18, 489-493.

Williams, D., Yee, N., \& Caplan, S. E. (2008). Who plays, how much, and why? Debunking the stereotypical gamer profile. Journal of Computer-Mediated Communication, 13(4), 993-1018.

Williams, D., Consalvo, M., Caplan, S., \& Yee, N. (2009). Looking for gender: Gender roles and behaviors among online gamers. The Journal of Communication, 59(4), 700-725.

World Health Organization. (2019). International classification of diseases (11th ed.). Geneva: World Health Organization.

Xuan, Z. M., \& Shaffer, H. J. (2009). How do gamblers end gambling: Longitudinal analysis of internet gambling behaviors prior to account closure due to gambling related problems. Journal of Gambling Studies, 25, 239-252.

Yousafzai, S. Y., Hussain, Z., \& Griffiths, M. D. (2014). Social responsibility in online videogaming: What should the videogame industry do? Addiction Research and Theory, 22, 181-185.

Zendle, D., \& Cairns, P. (2018). Video game loot boxes are linked to problem gambling: Results of a large-scale survey. PLoS One, 13(11), e0206767.

Publisher's Note Springer Nature remains neutral with regard to jurisdictional claims in published maps and institutional affiliations. 